


\section{Article Artículo Paper Treball social comunitari 3 com a base del procés de reinserció en els Centres Penitenciaris}

\section{Xavi Escribano ${ }^{1}$}

\author{
Eva Palasí
}

\section{Resum}

La participació dels professionals de l'àmbit social, especialment els professionals del treball social, és essencial a l'hora d'assegurar un procés de canvi efectiu en les persones privades de llibertat. Els treballadors socials han d'assumir un rol central i dinamitzador, en el que s'incorporin les diferents disciplines professionals que formen part dels centres penitenciaris. Aquest treball, eix central en el procés de desisitment de les persones privades de llibertat, té tres línies d'acció diferenciades: en primer lloc, conscientització de la realitat social en la que es troba la persona privada de llibertat, posteriorment, l'organització dels agents i recursos existents per facilitar el procés de reinserció i, en darrer terme, la mobilització dels recursos comunitaris per tal finalitat. El procés de transició a la llibertat passa a ser cabdal en l'èxit penitenciari ja que és on es posa en valor els aprenentatges realitzats $i$ on l'intern, s'enfronta a les situacions que l'han dut a la comissió del fet delictiu. L'article que presentem,

1. Sociòleg. Estudiant de doctorat en educació. Investigador del grup de recerca GIAS de la Facultat d'Educació Social i Treball Social Pere Tarrés - Universitat Ramon Llull.

2. Dra. per la Universitat Ramon Llull. Treballadora i Educadora social. Investigadora del grup de recerca GIAS de la Facultat d'Educació Social i Treball Social Pere Tarrés - Universitat Ramon Llull. 
sota una metodologia qualitativa en la que es dóna veu als propis agents implicats, posa en valor la importància del treball comunitari en el procés de reinserció i canvi identitari, liderat pels treballadors socials, en el que participen no només els professionals del centre, sinó també les entitats socials, els familiars i els propis interns.

Paraules clau: desistiment, reinserció social, interdisciplinarietat, Unitat Terapèutica i Educativa, conscientització, sensibilització comunitària. 


\section{La reinserció i el desistiment com a objectiu.}

La reinserció efectiva a la comunitat de les persones privades de llibertat, és el resultat d'un procés que s'inicia dins dels centres penitenciaris i continua després d'esgotar la condemna. Per assolir l'èxit d'aquest procés, materialitzat en l'abandonament de conductes de risc i delictives, resulta necessària la implicació de la comunitat i l'acompanyament dels professionals de l'àmbit social a l'hora de coordinar i gestionar els agents i recursos comunitaris.

El principal objectiu dels centres penitenciaris és el desistiment de les conductes antisocials i/o delictives de les persones privades de llibertat i la millora dels processos de reinserció. El desistiment delictiu és considerat per la criminologia com l'absència perllongada de determinats esdeveniments antinormatius (Laub i Sampson, 2001). En aquest cas, fem extensiu el concepte a les conducte i als comportaments susceptibles de desencadenar conductes delictives o anti-socials, junt a comportaments que assegurin un correcte procés d'incorporació comunitari. Aquest es defineix a partir de quatre components fonamentals (Loeber i Leblanc, 1990): Una desacceleració en la periodicitat dels indicadors de conductes anti-socials, una reducció en la varietat d'aquestes conductes, la reducció de la gravetat o perillositat de les mateixes, $i$, el fet que les conductes actuals mai arribin a superar en gravetat a les conductes inicials que han provocat l'internament. Però aquest procés de canvi necessita d'un suport comunitari i social que permeti consolidar-ho en el procés de transició a la llibertat. En definitiva, podem afirmar que el desistiment forma part d'un procés vital en el que la persona decideix per pròpia voluntat o a causa d'esdeveniments sobrevinguts (matrimoni, paternitat, malaltia, o un nou ingrés a presó, per mencionar alguns exemples) generar canvis identitaris que li permetin modificar la seva conducta, afavorint processos d'inclusió social.

Si bé el desistiment es considera un procés eminentment individual, no podem obviar els factors de vulnerabilitat presents en la trajectòria vital de la persona ni les limitacions que aquests factors suposen a l'hora de reinserir-se de manera efectiva i definitiva a la comunitat d'acollida. Les carències cognitives i emocionals, la manca d'estratègies psicològiques per afrontar les recaigudes, o les dificultats estructurals derivades de l'estada al centre penitenciari que poden dur a processos d'exclusió, com la dificultat per trobar feina o allotjament, analfabetització digital, o la debilitat de la xarxa social de l'ex-intern 
són indicadors d'alt risc de reincidència delictiva. La conducta dessistora s'ha de treballar a nivell individual i mantenir-la a través del suport comunitari, possibilitant la reducció de conductes anti-socials i delictives de forma sostinguda en el temps, $\mathrm{i}$ afavorint espais de suport que mantinguin aquest comportament. En aquest article posarem el focus en l'àmbit comunitari, concretament en les estratègies emprades pels i les professionals a l'hora d'implementar el treball social comunitari en les societats d'acollida dels ex-interns. El treball dels i les professionals en aquesta línia es basa en tres eixos principals: a) la conscientització de la realitat social en la que es troba la persona privada de llibertat, b) la organització dels agents i recursos existents per facilitar el procés de reinserció i c) la mobilització dels recursos comunitaris per tal finalitat. Cadascuna d'aquestes accions necessita de la implicació de diferents agents per a realitzar-se: el propi intern, els i les professionals del centres penitenciaris i les entitats presents en el territori i la comunitat.

\section{L'entorn penitenciari com a espai educatiu i de canvi}

La Unitat Terapèutica i Educativa (UTE) del Centre Penitenciari d'Astúries (anteriorment CP Villabona ${ }^{3}$ ) naix el 1992 com una alternativa a l'actual model penitenciari, basat en estratègies de tipus educatiu i comunitari. El seu ojectiu és el de possibilitar processos de reinserció a través de possibilitar canvis identitaris de la persona (Enjuanes et alt,2014). Per aconseguir-ho, el model basa el seu treball en la instauració de processos de coparticipació i cogestió dels propis interns, alhora que es potencia el treball interdisciplinari i comunitari, tant dins el Centre Penitenciari, com en el procés de transició a la llibertat.

Lexecució penal i el procés de canvi requereix d'una mirada professional capaç d'incloure diferents perspectives i maneres de fer que comparteixin un objectiu comú i que, al mateix temps enriqueixi i capaciti als agents implicats. En el cas de la UTE, el treball interdisciplinari resulta, no només adequat, sinó imprescindible per articular amb èxit les propostes educatives. Ens referim com a treball interdisciplinari a la convergència de professions i disciplines que treballen des de projectes compartits. La interdisciplinarietat es troba així associada amb la creativitat, tant pel que fa a la innovació i a l'associació d'idees

3. Per Ordre INT/1231/2017 el Ministeri de l'Interior canvi el nom del Centre Penitenciari Villabona pel de Centre Penitenciari Astúries 
diverses amb una naturalesa comuna, com en la mesura en que la pròpia interdisciplinarietat esdevé font de renovació i invenció (Rugarcía, 1996).

El model de treball interdisciplinari de la UTE es centra en el treball integral, que aporta una major eficiència i rendibilitat del sistema. Aquest model es basa en: a) Una organització horitzontal que requereix d'un alt grau d'implicació per part de tots els i les professionals i que aporta una gran riquesa a l'equip i al treball que es duu a terme; b) el canvi de rol de vigilant a educador permet el treball des d'una perspectiva integral i integrada de la intervenció; c) la millora del clima laboral fruit d'objectius de treball en comú i del reconeixement mutu dels membres de l'equip; d) la importància de les reunions diàries i del treball continu i sistemàtic i e) la riquesa de visions des de la diversitat professional.

Aquest treball permet establir les estratègies tant individuals com col-lectives que han de permetre l'assoliment dels objectius, que no són altres que la consolidació de processos desistors i l'acompanyament cap a processos de transició a la llibertat que facilitin la inclusió social. Aquests treball, si bé està pivotat i dirigit per equips amb representació de diverses disciplines, és necessari que sigui compartit també amb la resta dels agents socials que intervenen en el treball educatiu: les entitats socials, les famílies i, especialment, els propis interns.

Des de la UTE, es considera a tots i cadascun d'aquests agents com a promotors de l'acció educativa i com a agents de canvi. El manteniment en comunitat del procés de desistiment necessita d'una intervenció multi estratègica que inclogui: a) intervencions individuals i de canvi a través de la conscientització i voluntat de canvi; b) intervencions grupals liderades per professionals a través de programes i projectes d'intervenció competencials; c) intervencions grupals entre el grups d'iguals de foment de valors socials; i, d) intervencions d'acompanyament i reforç a la comunitat, que permetin mantenir el treball realitzat dins la UTE.

El que us presentem en el present article és el treball que es realitza a la UTE del CP d'Astúries, en relació al procés de canvi identitari i millora del procés de reincorporació social. A través de donar veu als participants a l'estudi mostrarem els resultats més significatius en aquesta línia, i la importància de la intervenció interdisciplinària per tal de poder-los assolir. 


\section{Metodologia}

Aquest article s'emmarca dins la recerca "Pedagogia Social Comunitària en centres penitenciaris i programes de reinserció social" duta a terme pel grup de recerca GIAS de la Facultat d'Educació Social i Treball Social Pere Tarrés, de la Universitat Ramón Llull. En aquest article, s'exposaran les dades corresponents a la recerca realitzada a la Unitat Terapèutica i Educativa (UTE) del centre penitenciari Astúries. Les dades que exposem en aquest escrit corresponen a la primera fase de la recerca, on es va emprar un disseny metodològic qualitatiu d'estudi de casos (Stake, 1998, 1995, Yin, 1984). Degut a la absència d'estudis previs en aquest camp, es va recórrer al mètode de la teoria fonamentada (Glaser y Strauss, 1967) per l'anàlisi i interpretació de les dades.

Durant la recerca es va comptar amb la participació dels propis interns, els professionals del centre (tant de tractament com de vigilància), voluntariat i els familiars dels interns. A la Taula 1 es poden consultar les tècniques de recollida de dades, la quantitat de persones participants, el grup al que pertanyen i la durada de cada sessió.

Taula 1: Tècniques emprades i participants de la recerca

\begin{tabular}{|c|c|c|c|}
\hline Tècniques & Participants & Grup & Durada \\
\hline Grups de discussió & $\begin{array}{l}8 \text { grups amb total } \\
\text { de } 126 \text { participants }\end{array}$ & $\begin{array}{l}\text { Professionals, } \\
\text { voluntaris, interns }\end{array}$ & $60-90$ minuts \\
\hline $\begin{array}{c}\text { Entrevistes en } \\
\text { profunditat }\end{array}$ & 39 & $\begin{array}{l}\text { Famílies, interns, } \\
\text { professionals }\end{array}$ & $60-90$ minuts \\
\hline Històries de vida & 27 & Interns i ex interns & $90-120$ minuts \\
\hline $\begin{array}{l}\text { Observació } \\
\text { participant }\end{array}$ & 10 & Professionals & Activitat \\
\hline TOTAL & 202 & & \\
\hline
\end{tabular}

Abans de realitzar la recollida de dades, es va contactar amb l'equip directiu del centre, a qui se li va explicar l'objectiu de la recerca i els perfils de participants necessaris per la investigació. L'adequació dels participants depenia, principalment, del coneixement i l'experiència respecte al funcionament de la UTE i de la seva capacitat cognitiva i comunicativa. Identificats els participants potencials, tant per l'equip directiu com per l'equip de 
recerca, s'hi va contactar per explicar el projecte i proposar-los-hi participar. La col-laboració en l'estudi ha estat voluntària i s'ha comptat amb el consentiment informat de totes les persones participants, tot garantint el seu anonimat mitjançant la codificació de les seves dades personals.

La recollida de dades es va realitzar en tres moments diferents al llarg dels dos anys que ha durat el treball de camp de la investigació. Les dades es van analitzar amb el programa Atlas.ti, a través de la codificació axial de les entrevistes a partir d'un arbre de codis obert dissenyat per la investigació. En total es van identificar 51 codis agrupats en 4 famílies diferents (objectius de la UTE, metodologies aplicades, agents participants, i contextos). Un cop es van tenir les entrevistes codificades, i a través del treball conjunt entre els diferents membres de l'equip investigador, s'han destacat els elements reiteratius assenyalant identificar els resultats significatius.

\section{Resultats}

A continuació es descriuen els principals resultats de la recerca, que hem disposat en tres blocs. En primer lloc la manera en que es concep i duu a terme el treball interdisciplinari dins la UTE. A continuació descriurem com aquest es materialitza en la manera en que s'organitza el treball a la UTE, i, en tercer lloc les línies d'acció dels equips professionals tant dins del centre penitenciari com envers la futura comunitat d'acollida.

\subsection{Treball interdisciplinari}

Respecte al treball interdisciplinari a la UTE, es destaca la riquesa que aporta el treball i l'organització de tipus horitzontal de l'equip de professionals. Aquest equip està format per diferents figures professionals (psicòlegs, educadors socials, treballadors socials, mestre professionals de vigilància) que comparteixen un mateix objectiu, i que a través del respecte mutu entre les diferents figures i funcions que realitzen, possibiliten l'èxit dels processos terapèutics i educatius amb els interns. Així ho recullen els coordinadors de la UTE en les següents aportació: 
Això entraria dins el que seria com es genera aquesta estructura horitzontal, i com es manté, doncs això s'aconsegueix des de la trobada permanent, o sigui, vull dir, tots els dies ens trobem, tots els dies, tots els dies estem intercanviant impressions. Tots els dies, d'alguna manera, estem revisant el projecte i el que estem revisant, d'alguna manera és el que és el dia a dia. Les dificultats amb la institució, doncs, els sistemes rotatius amb els quals funciona a les presons.

Coordinador UTE

Un altre aspecte destacable del treball interdisciplinari en la UTE és el canvi de rol de vigilant a educador que possibilita a aquests professionals desenvolupar un major nombre de funcions i, la seva implicació en tot el procés de canvi dels interns. Un dels interns fa referència a aquest canvi amb la següent reflexió.

Em va fer canviar sobretot el concepte de guàrdia o de carceller em va canviar perquè precisament aquells que jo mai vaig pensar que m'anaven a ajudar van ser els que em van treure realment del pou en el qual... no veia sortida. Llavors, ells van ser els que van ficar la mà en aquest aigua bruta en el qual jo estava ficat i em van rescatar. Inter_agent de salut

\subsection{Organització de la Unitat Terapèutica i Educativa}

La voluntat de canvi proposada pel model UTE es materialitza en la creació de l'equip multidisciplinari i l'equip de coordinació. Es tracta d'estructures professionals dissenyades per coordinar esforços de cara a un procés de reinserció efectiva. Aquestes estructures estan formalitzades en els manuals de formació interns de la Unitat i, si bé no es consideren òrgans col-legiats de la institució penitenciària, són part de l'estructura de la pròpia unitat. A continuació es presenta la definició i funcions de cada un dels equips:

Equip Multidisciplinari: Màxim òrgan de decisió de la UTE. Integrat per tots els treballadors dels diferents àmbits de la institució: funcionaris, educadors, treballadors socials i psicòlegs, amb especial rellevància dels funcionaris de vigilància. Les funcions específiques de l'equip són: a) marcar les línies generals d'actuació, b) planificar les activitats a desenvolupar en cada jornada, i especialment la distribució de la realització dels diferents grups terapèutics; c) resoldre les vicissituds que es produeixen diàriament; d) proposar els 
ingressos en la Unitat i les expulsions; e) suggerir sobretot tipus de beneficis penitenciaris if) plantejar les derivacions a diferents centres terapèutics.

Equip de coordinació: Equip que coordina el treball dels professionals dels diferents sectors professionals i concerta els mitjans i esforços per a l'acció conjunta dels professionals de la UTE per afrontar l'activitat diària i l'assoliment dels objectius de la unitat. Les funcions específiques de l'equip de coordinació són: a) distribuir les tasques de treball diàries; b) atendre els conflictes que sorgeixin en el marc de l'equip; c) coordinar-se amb la Sots-direcció de Tractament del Centre Penitenciari; d) representar a l'equip davant la direcció del centre i les entitats públiques i privades que intervenen en el mateix; e) elaborar i presentar la memòria anual i f) informar a l'equip sobre tots aquells assumptes relacionats amb la UTE.

Els professionals entrevistats fan referència a aquestes funcions amb les següents expressions:

Ells com a tutors, els companys de vigilància, són els que proposen coses, o millor dit, proposen tot en relació a la vida de l'intern: permisos, sortides terapèutiques, derivacions, en art 182, etc... Llavors els dones bastant protagonisme, de cara en el dia a dia quan ells et comenten diferents problemes que poden tenir els interns.

Coordinador UTE

La relació que s'estableix entre interns i professionals és descrita pels primers en termes de proximitat, escolta i, en algun cas, amistat. Un dels interns expressa amb la següent frase la seva relació amb els professionals de vigilància:

Em va fer canviar sobretot el concepte de guàrdia o de carceller em va canviar perquè precisament aquells que jo mai vaig pensar que m'anaven a ajudar van ser els que em van treure realment del pou en el qual no veia sortida. Llavors, ells van ser els que van ficar la mà en aquesta aigua bruta en el qual jo estava ficat i em van rescatar. Intern_agent de salut

Un aspecte de màxima importància per treballar des de les claus descrites és la consideració que el professional ha de creure i estar convençut que la seva actuació sempre 
serà educativa, i des d'aquí també la seva responsabilitat comunitària. Així ho plantegen dos dels professionals de la UTE:

E1 treball no et satura en cap dels mòduls. És una tasca més aviat rutinària, saps que aquí tens una càrrega extra de treball i has de venir amb l'actitud de voler assumir aquesta càrrega de treball, perquè també vens perquè vols, és voluntari.

Funcionari

Si no tens una implicació mai tindràs una pertinença sempre aniràs a treballar. La implicació a poc a poc et va omplint i és quan et vas implicant més. Canviar el xip, és a dir, tu ja no ets un funcionari ras de l'altre costat, d'obrir i tancar portes. Tu et vas a tenir que asseure, a escoltar... En el buc, l’oficina és la meva casa, ara ja deixa de ser la meva casa, ara és la nostra casa.

Educador

Es destaca també el treball que els professionals de l'equip interdisciplinari realitzen amb les famílies dels interns, com a element rellevant del seu procés de canvi i de reinserció. Així ho explica un dels interns de la UTE:

Dels professionals et dic, a mi em va tocar, per exemple, un professional molt bo, em va tocar de tutor, jo portava sense saber gens de la meva mare des dels 17 anys, és més jo vaig caure pres i no vaig avisar a la família per res i bé doncs el tutor totes les setmanes va intentar parlar amb la meva mare perquè vingués a veure'm o que almenys que sabés com estava.

Exintern de la UTE

\subsection{Línies d'acció}

El treball envers la reinserció social i el desistiment s'articula en accions orientades als dos àmbits fonamentals de la reinserció, representats pel canvi personal dels propis interns i per la comunitat que els haurà d'acollir en el futur. Les accions en aquestes àrees es concreten, d'una banda, en la concientització dels interns i, per altra banda, en la mobilització de la comunitat que acollirà a l'intern una vegada hagi complert el seu temps de condemna. Ambdues es reconeixen com igualment importants de cara a assolir un procés 
reinserció efectiva i requereixen d'un alt grau d'implicació per part dels diversos agents que hi participen.

\section{Conscientització}

La presa de consciència de la situació present de l'intern consisteix en adquirir una visió ajustada a la realitat de les pròpies limitacions i capacitats, així com la responsabilització, tant dels actes passats com de les accions futures per assolir un canvi profund i significatiu. Tot i que es tracta d'un procés imprescindible per poder assolir el desistiment, no està exempt de dificultats ja que, en la majoria de casos, l'intern ha desenvolupat una imatge distorsionada de sí mateix, així com dels fets que l'han dut a complir condemna. D’altra banda, la Unitat Terapèutica i Educativa i els seus educadors i educadores compten amb diverses estratègies i metodologies dissenyades precisament per conscienciar als interns i, conseqüentment, ferlos més receptius als aprenentatges que puguin realitzar a l'UTE.

a) Carta de presentació

En la carta de presentació, l'intern narra la seva trajectòria vital i expressa la seva motivació i expectatives per començar el procés de canvi. L'auto-narrativa es considera un element fonamental en el procés de desistiment (Maruna, 2000) ja que permet, comprendre el passat, té també efectes significatius en el present i el futur al iniciar un cicle emocional on la persona veurà condicionades les seves disposicions actuals (Vaughan, 2007).

El procés d'inici del canvi terapèutic passa per una primera fase d'acceptació dels factors que han provocat la comissió del delicte i el rebuig a la norma legal, que genera conductes de tipus antisocial. Tots aquests elements s'intenten resumir en la carta de presentació, en un primer moment, i en els grups terapèutics, posteriorment. Així viuen els interns la lectura de la seva carta de presentació:

Estic recuperant sentiments que no tenia. M'estic adonant, després d'aquesta carta, que he sofert i ploro, i al final és un sentiment d'alleujament. Estic recuperant aquests valors que he perdut. I a poc a poc, conscientment, mestic adonant que arribi el permís o sortir abans no és tan important. L'important és viure.

Intern 
No, no és faccil perquè fora no la faries mai en la vida, et moriries i una persona que no entri en la Unitat mai faria una carta de presentació. Ni algú que té un diari fa el que fa una persona aquí dins, com fer una carta de presentació. És impossible perquè comences des del principi i has de basar-te en sentiments, simplement, tornar a l'origen, i dir, doncs mira els meus primers records i a més no és asseure't i escriure-la sinó que has de buscar el teu el moment adequat en el qual estàs pensant... Intern

Els moments crucials de la vida d'una persona no són provocats per fets reals sinó per les revisions efectuades en el relat que un ha estat utilitzant per explicar els successos (Bruner i Weiser, 1995). El treball d'acompanyament en el procés de canvi implica la necessària consideració de l'intern com ser únic:

Es treballa des d'una metodologia de coneixement propi i de la resta, sota la més estricta realitat pura i dura que veiem els qui som, com som i que fem a la vida. Grup de discussió 2 Interns.

Un intern ho expressa així durant un grup de discussió:

Aquí tu arribes i el primer que et pregunten com està la teva mare, com estan els teus germans, i els teus familiars, entens?. Això és l'important en la vida.

Grups de discussió 3 interns

b) Contracte terapèutic

Una altra estratègia utilitzada pels equips educatius és la redacció del contracte terapèutic i la seva signatura per part de l'intern. Aquest document inicia la narrativa del canvi i vincula als interns amb la unitat i el treball que s'hi desenvolupa, el compromís i l'exercici dels seus drets i el compliment dels seus deures. El contracte terapèutic busca, d'una banda, formalitzar el compromís de l'intern amb el seu procés de canvi mitjançant un conjunt de pautes dirigides a construir una relació transparent i lliure de conflictes amb el mòdul terapèutic. D'altra banda, amb el contracte es pretén garantir que el procés educatiu i terapèutic es porti a terme en les millors condicions possibles. Els objectius del contracte terapèutic són (Ministerio del interior, 2005): 1) desintoxicació i deshabituació 
en les persones afectades per la seva addicció a les drogues; 2) la integració i estabilització de les persones amb llarga trajectòria tòxico-fílica en programes de disminució de danys; 3 ) adquirir mecanismes i actituds que ajudin a reforçar el procés personal de canvi i l'abandonament de les conductes delictives per part de l'intern; 4) interioritzar hàbits i habilitats socials que li permetin adoptar una forma de vida saludable; 5) educar en valors i actituds pro-socials; 6) Promoure una utilització positiva del temps lliure; 7) iniciar i/o reiniciar estudis inacabats o un altre tipus de formació; 8) treballar la comunicació i les relacions positives entre les persones; 9) fomentar aspectes de creixement personal com l'autocontrol, autoestima, sinceritat i responsabilitat i 10) incentivar les relacions familiars.

Ambdues metodologies ajuden a l'intern en el seu desenvolupament, passant d'una perspectiva centrada en la pròpia persona a processos de raonament moral més heterònomes i des de la comprensió de la persona com a membre d'una societat (Trilla, 2010). Aquesta realitat permet evidenciar i formalitzar un procés de desistiment (Cid, 2011; Laub i Sampson, 2001) que faciliti l'abandó d'accions delictives i la millora dels processos d'incorporació social.

\section{Mobilització de la comunitat: sensibilització social}

L'adaptació a la vida del centre penitenciari requereix un conjunt de canvis, en la manera de relacionar-se i comunicar-se amb els demés i la interiorització d'un conjunt de pautes i normes de comportament que no s'apliquen a la societat fora del centre. Una vegada en llibertat, la persona deixa de tenir accés als espais segurs, com el grup de suport o les tutories amb l'educador referents, esdevenint l'única responsable de la seva actitud en comunitat. La transició a la llibertat, doncs, pot resultat en sí mateixa un factor de risc a recaure en la conducta delictiva, especialment en aquells ex-interns que presenten factors de risc d'exclusió social. Per aquest motiu, és fonamental que la persona que surt en llibertat tingui una bona relació amb la comunitat i, encara més important, que la comunitat es presenti com un entorn integrador i segur.

La mobilització de la comunitat es basa en tres elements interrelacionats: la sensibilització social, l'apoderament comunitari i el sentiment de comunitat. Tanmateix, En aquest article en centrarem en la sensibilització social, que és el primer pas envers la mobilització de la comunitat i és l'element en el que el que es pot incidir directament des de la UTE. 
La sensibilització social s'entén com un conjunt d'accions pedagògiques i comunicatives encaminades a generar canvis i modificacions en l'imaginari social que permetin avançar cap a situacions socials més satisfactòries (Carmona i Rebollo, 2009). Es defineix també com "un procés educatiu constant que afavoreix la comprensió de les interrelacions econòmiques, polítiques, socials i culturals entre el Nord i el Sud; promou valors i actituds relacionades amb la solidaritat i la justícia social i busca vies d'acció per aconseguir un desenvolupament humà i sostenible.”(AECID, 2005, p.101).

\section{Accions per a la sensibilització social}

Des de la UTE, es treballa fonamentalment des de l'àmbit de la sensibilització social en dos sentits: 1) sensibilitzant a la comunitat sobre la situació dels interns i la possibilitat del canvi i 2) sensibilitzant als interns sobre la necessitat de canviar la seva percepció i la seva relació amb la societat.

Les accions de la UTE en aquest sentit es reserven a aquells interns que presenten avenços en el seu procés de canvi. Aquesta restricció es deu a que es tracta d'accions que requereixen sortir del centre penitenciari i requereixen que hagin assumit la responsabilitat de la seva trajectòria vital.

Les accions orientades a la comunitat des de la UTE són la sortida terapèutica ${ }^{4}$, les sortides ordinàries ${ }^{5} \mathrm{o}$ de règim i el programa de prevenció de consum d'alcohol i altre drogues.

a) Sortida terapèutica

Actuació intermèdia de valor terapèutic entre l'activitat que es desenvolupa a l'interior del CP i els permisos de sortida. Presenta un menor grau d'autonomia de l'intern respecte als permisos al comptar amb la supervisió per part dels professionals de la UTE o dels professionals de l'organització col-laboradora responsable de l'activitat.

Les funcions de la sortida terapèutica són 1) Observar la conducta de l'intern en un context exterior. 2) Treballar aspectes en els quals l'intern presenta dèficit. 3) Reforçar

4. 1 i 2 Ministeri de l'Interior, 2005

5.1 i 2 Ministeri de l'Interior, 2005 
una evolució conductual positiva. 4) Promoure una eficaç dinàmica de treball en grup, que faciliti actituds de comunicació i solidaritat entre els interns. 5) Preparar per a la sortida de permisos ordinaris. 6) Donar sortida a situacions personals d'interns que bé per circumstàncies penals-penitenciàries o raons socials no aconsellin la concessió del permís.

b) Sortides ordinàries o de règim

Instrument fonamental en el procés de reinserció que inicien els interns a la UTE. Els situa en un marc real de convivència que l'obliga a posar en joc el treball realitzat en relació a la responsabilitat i la implicació personal.

Amb les sortides ordinàries o de règim es pretén 1) Desenvolupar hàbits i habilitats socials apresos en el procés terapèutic de canvi.2) Facilitar el desenvolupament en un espai normalitzat, allunyat d'ambients marginals i delinqüencials. 3) Enfortiment de la comunicació familiar i inici de relacions positives. 4) Aprendre una correcta utilització dels recursos socials que la comunitat posa al seu abast. 5) Utilitzar de forma positiva el temps lliure i d'oci, descobrint noves activitats que li produeixin satisfacció personal.

c) Programa de prevenció consum del d'alcohol i altres drogues

La UTE del CP d'Asturies proposa als centres escolars de la comunitat accions de prevenció del consum de drogues amb una doble finalitat: 1) sensibilitzar i conscienciar als alumnes a través dels testimonis personals i el diàleg amb els interns en relació a la prevenció del consum d'alcohol i altres drogues i 2) minimitzar els possibles impactes negatius assenyalats per algunes recerques per a aquest tipus de proposta. Les visites als centres penitenciaris són per a la UTE un espai de sensibilització social, i especialment de sensibilització al col·lectiu de joves, les seves famílies i els seus professors.

Aquesta activitat té les funcions de: 1) Aportar elements de reflexió en relació a la prevenció en el consum de drogues. 2) Acostar la presó al medi escolar, desmitificant estereotips negatius. 3) Aportar una dimensió més humana a les situacions d'exclusió social i fomentar actituds de solidaritat dels adolescents i joves. 4) Conèixer en primera persona la realitat del món penitenciari. 5) Generar processos d'empatia cap al col·lectiu d'interns. 
Per a permetre als joves entendre les circumstàncies que porten a una persona a cometre delictes i, per extensió. 6) Generar processos de prevenció general positiva entre els joves.

\section{Conclusions}

Totes les accions i iniciatives que hem descrit en aquest article no serien possibles sense el treball interdisciplinari i la implicació activa d'un ingent nombre de persones de perfil, capacitats i visions molt diverses que, no obstant, s'organitzen i treballen amb un objectiu comú. Treball que està organitzat i estructurat per tal d'assolir els objectius constitucionals de la reeducació i la reinserció.

El relat de les persones entrevistades descriu el treball interdisciplinari com a eix principal de les accions que es duen a terme a la UTE. Aquest no només representa beneficis a nivell organitzatiu, com una major capacitat d'adaptació i flexibilitat per part dels professionals i els voluntaris, sinó que també contribueix a la superació per part dels interns de les idees clàssiques de confrontació entre els professionals, principalment de vigilància, i els propis interns. El contacte permanent i horitzontal entre els agents contribueix també a la adquisició de noves competències professionals i de nou coneixement sobre aspectes fonamentals en el procés de transició a la llibertat que poden no formar part dels requisits inicials per dur a terme les pròpies funcions professionals.

Més enllà dels beneficis pels agents implicats en la UTE, el treball interdisciplinari té també efectes en la comunitat externa al centre penitenciari. La interacció, acompanyada per diversos perfils professionals, dels interns amb els seus potencials veïns i veïnes resulta fonamental per facilitar el procés de transició a la llibertat. En aquest sentit, volem mencionar especialment els beneficis del programa de prevenció d'alcohol i altres drogues en els instituts, que té un efecte especialment beneficiós en els interns que hi participen. Aquest es deu al fet que els participants consideren que estan retornant una part del que han "pres" a la societat en la comissió del delicte i la idea que la seva aportació pot ajudar als adolescent a evitar una trajectòria vital com la seva.

En definitiva, el treball interdisciplinari s'ha identificat per part de les persones participants en aquest estudi com la millora manera d'abordar una situació multi-problemàti- 
ca i enormement complexa com és la reinserció social després del compliment d'una pena a un centre penitenciari. Des d'aquest escrit volem encoratjar a la consideració de la interdisciplinarietat com a model de treball en experiències semblants a la UTE en el futur.

\section{Bibliografia}

Bruner, J. y Weiser, S. (1995) La invención del yo. La autobiografia y sus formas en Torrance, N. y Olson, D. (coord.) Cultura escrita y oralidad Barcelona: Gedisa

Caride, J.A.; Lopez, J.F. (2002) Ocio y voluntariado social: solidaridad cívica y tiempo libre, Bilbao, Documentos de Estudios de Ocio.Universidad de Deusto, no 21

Carmona, M.; Rebollo, O. (2009). Guia operativa d'acció comunitària. Acció Social i Ciutadania. Ajuntament de Barcelona.

Cid,J. (2011) El procés de desistiment de les persones empresonades. Obstacvles i suports Barcelona: CEJFE

Enjuanes. J., Garcia, F. i Longoria, B. (2014) La Unidad Terapéutica y Educativa del Centro Penitenciario de Villabona, un nuevo modelo penal de reinserción social a Revista Educació Social. Revista d'intervenció socioeducativa vol 57

Glaser, B. y Strauss, A. (1967). The discovery of grounded theory: strategies for qualitative research. New York: Aldine publishing

Laub, J.; Sampson, R. (2001). "Understanding desistance from crime”. En: Crime and Justice, núm. 28 p. 1-69

Maruna, S. (2000) Making good: How exconvicts reform and rebuild their lives Washington: American psichological association books

Ministerio de Asuntos exteriores y cooperación. Plan Director de la Cooperación Española 2005-2008 
Minuchin, S. y Fishman C. (2006) Técnicas de Terapia Familiar. Editorial. PAIDOS.

Loeber, R. and Le Blanc, M. (1990) “Toward a Developmental Criminology,” Crime and Justice12: 375-473.

Rugarcía, A. (1996) Educar en valores. México: Universidad Iberoamericana

Stake, R. (1998). Investigación con estudio de casos. (Morata, Ed.). Madrid.

Stake, R. E. (1995). The Art of Case Study. (Sage, Ed.). London.

Trilla,J. (2010) Propuestas conceptuales para clarificar el debate sobre la educación para la ciudadanía en la escuela en Puig, JM (coord.) Entre todos. Compartir la educación para la ciudadanía Barcelona: ICE-Horsori

Vaughan, B. (2007) The internal narrative of desistance en British Journal of Criminology num 47(03) pp 390-404

Yin, R. (1984) Investigación sobre estudio de caso. Diseño y métodos. Londres. Editorial SAGE 
Xedagogia i Treball Social

Revista de Ciències Socials Aplicades

Edita: Universitat de Girona

Disseny i maquetació: info@clam.cat · 647427732

Dipòsit Legal: GI.904-2010

ISSN: 2013-9063 